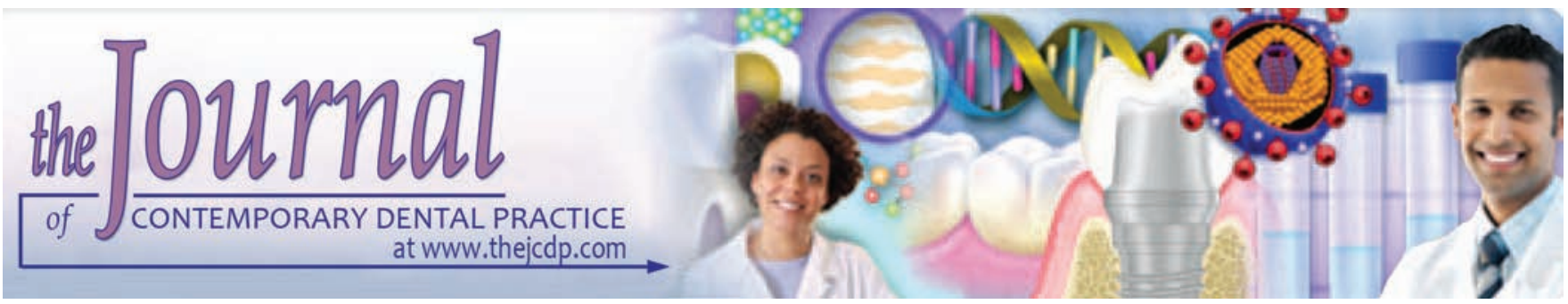

\title{
Histologic Variants of Calcifying Odontogenic Cyst: A Study of 52 Cases
}

\author{
${ }^{1}$ Soussan Irani, ${ }^{2}$ Forough Foroughi
}

\begin{abstract}
Aim: This study aimed at evaluating histological features of 52 cases of calcifying odontogenic cyst (COC), which is an uncommon benign odontogenic lesion. The World Health Organization (WHO) classified COC as a neoplasm and used the term calcifying cystic odontogenic tumor (CCOT) for benign cystic type and the dentinogenic ghost cell tumor (DGCT) for the benign solid-type lesions. There is no agreement regarding COC classification.
\end{abstract}

Materials and methods: A total of 52 cases of COC were selected and reviewed from the archive of the Pathology Department of Taleghani Educational Hospital, Tehran, Iran. To better understand the pathogenesis of $\mathrm{COC}$, the cases were classified.

Results: There were 52 cases ( 31 males and 21 females). The lesion was found in all age groups, and patients' age from 8 to 61 years. Nineteen cases affected the maxilla, and 33 cases affected the mandible. Except two cases, all were intraosseous lesions. Radiographically, 30 cases showed a unilocular radiolucent area, and 22 cases showed a mixed radiolucent/ radiopaque region. Histopathologically, 43 cases were cystic type and 9 cases were neoplastic.

Conclusion: There are two different histopathological entities. In view of these findings, it is very difficult to determine every lesion that has a cystic architecture is truly cystic or is a neoplastic one in nature. It is believed that the solid variants may be neoplastic.

Clinical significance: A better understanding of the histological type of the lesion can provide a classification across patients. This can help in treatment planning to improve patient outcomes.

\footnotetext{
${ }^{1}$ Department of Oral Pathology, Dental Faculty, Dental Research Centre, Research Centre for Molecular Medicine, Hamadan University of Medical Sciences, Hamadan, Iran

${ }^{2}$ Department of Pathology, Taleghani Hospital, Shahid Beheshti University of Medical Sciences, Tehran, Iran

Corresponding Author: Soussan Irani, Department of Oral Pathology, Dental Faculty, Dental Research Centre, Research Centre for Molecular Medicine, Hamadan University of Medical Sciences, Hamadan, Iran, Phone: +988138354250 , e-mail: sousanirani@gmail.com
}

Keywords: Calcifying odontogenic cyst, Neoplasm, Odontogenic.

How to cite this article: Irani S, Foroughi F. Histologic Variants of Calcifying Odontogenic Cyst: A Study of 52 Cases. J Contemp Dent Pract 2017;18(8):688-694.

Source of support: Nil

Conflict of interest: None

\section{INTRODUCTION}

Calcifying odontogenic cyst is an uncommon benign odontogenic lesion that was introduced by Gorlin et $\mathrm{al}^{1}$ for the first time in 1962. The WHO classified COC as a neoplasm and used the term calcifying cystic odontogenic tumor (CCOT) for benign cystic type, the DGCT for the benign solid type lesions which occur centrally or peripherally, and the malignant ghost cell odontogenic carcinoma. $^{2-5}$

The most common histopathological findings include a cystic lesion lined by epithelium with a well-defined basal layer of columnar cells, an overlying layer with many cells resembling stellate reticulum, and masses of ghost epithelial cells that may be in the epithelial cyst lining or in the fibrous capsule. The ghost epithelial cells may become calcified. Dysplastic dentin may be seen adjacent to the basal layer of the epithelium. ${ }^{6,7}$ In addition, COC may contain some areas suggestive of neoplasm; 8 however, most of the cases are non-neoplastic. ${ }^{9}$ There is no agreement regarding COC classification. In this article, histopathological variants of 52 cases of COC have been discussed.

\section{MATERIALS AND METHODS}

A total of 52 cases of COC were selected and reviewed from the archive of the Pathology Department of Taleghani Educational Hospital, Tehran, Iran. For a better understanding of the lesion pathogenesis, the cases were classified as shown in Table 1. 
Table 1: Classification of COC

Type I: Cystic type

(A) Simple cyst (nonproliferative)

(B) Proliferative cyst

(C) Ameloblastomatous type

(D) Associated with odontoma

Type II: Neoplastic type

(A) Ameloblastoma ex-COC

(B) Associated with other odontogenic tumors

(C) CDGCT

(D) PDGCT

(E) Malignant COC

CDGCT: Central dentinogenic ghost cell tumor; PDGCT: Peripheral dentinogenic ghost cell tumor

\section{RESULTS}

Of 52 cases, 31 were males and 21 were females. The lesion was found in all age groups, and patients' age from 8 to 61 years. The mean age in all cystic variants was 26.2 years. The mean age for patients with neoplastic type was 37.2 years. Nineteen cases affected the maxilla $(36.5 \%)$, and 33 cases $(63.5 \%)$ affected the mandible. Except two cases, all were intraosseous lesions. Thirteen cases involved the midline and anterior region. Radiographically, 30 cases showed a unilocular radiolucent area, and 22 cases showed a mixed radiolucent/ radiopaque region. Histopathologically, 43 cases $(82.7 \%)$ were cystic type and 9 cases $(17.3 \%)$ were neoplastic. The cystic type occurred in four variants: (1) Simple cyst (16 cases; $30.8 \%$ ), characterized by a simple unicystic structure with a stratified epithelial lining of 4 to 10 cells thick comprising basal columnar or cuboidal polarized cells, and clusters of ghost cells and calcified materials (Fig. 1). Epithelium budding into the connective tissue was found in some cases. In cases of merging the ghost cells to the fibrous cyst wall, cholesterol granuloma was

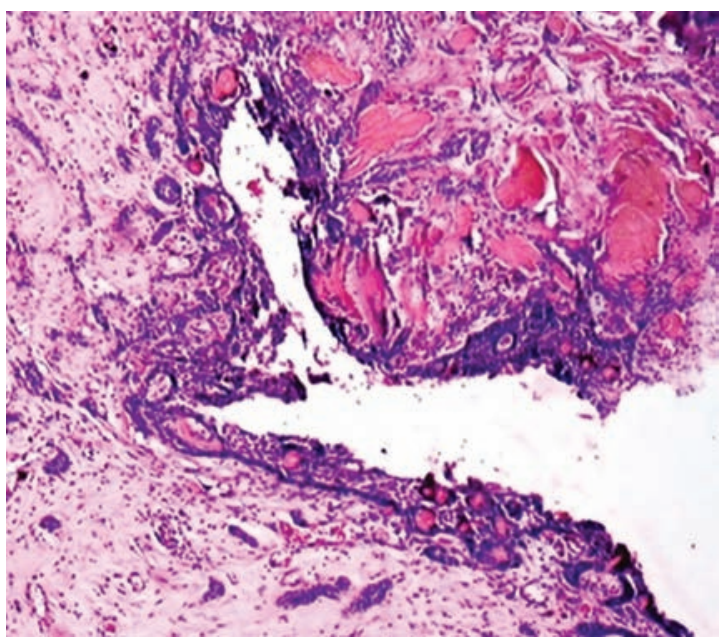

Fig. 2: Low-power view shows proliferative type characterized by epithelial-lined cyst and multiple daughter cysts in the cyst wall. Notice the extensive ghost cell formation

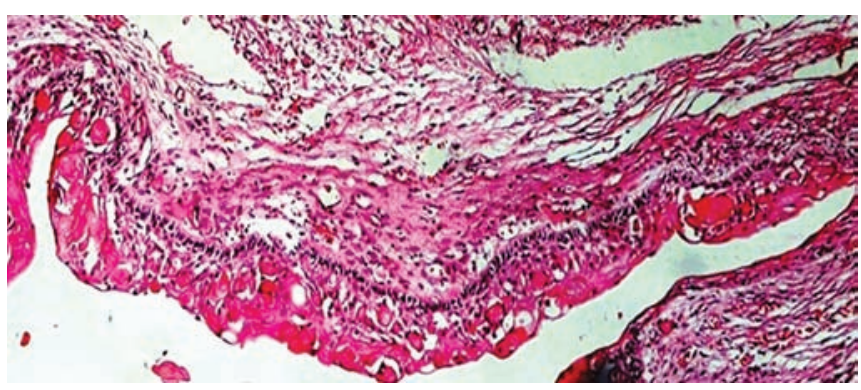

Fig. 1: Higher magnification shows a simple unicystic structure with a stratified epithelial lining and clusters of ghost cells

seen. (2) Proliferative type (8 cases; $15.4 \%$ ), characterized by a relatively thick epithelial-lined cyst with multiple daughter cysts in the cyst wall (Fig. 2). Extensive ghost cell formations, with a marked tendency for calcification, and foreign body reaction to the herniated ghost cells and cholesterol clefts were the other microscopic features for this type. (3) Cystic lesions associated with odontoma (16 cases; $30.8 \%$ ), with combined features of COC (presence of ghost cells) and odontoma (Fig. 3). (4) Ameloblastomatous type (4 cases; 7.7\%), characterized by a unicystic structure lined by unifocal or multifocal intraluminal epithelial proliferation resembling ameloblastoma without Vickers and Gorlin signs along with clusters of ghost cells and calcifications (Fig. 4).

The neoplastic type occurred in four variants: (1) Ameloblastoma ex-COC or ameloblastoma arising in COC (3 cases; 5.8\%), which showed a cystic structure lined by odontogenic epithelium with early ameloblastomatous changes with features suggested by Vickers and Gorlin. Multifocal intraluminal and intramural proliferations showed transformed ameloblastomatous epithelial part. In one case, ameloblastomatous proliferation was in the plexiform pattern (Fig. 5A), and in one case it was in the follicular pattern (Fig. 5B). The transformed

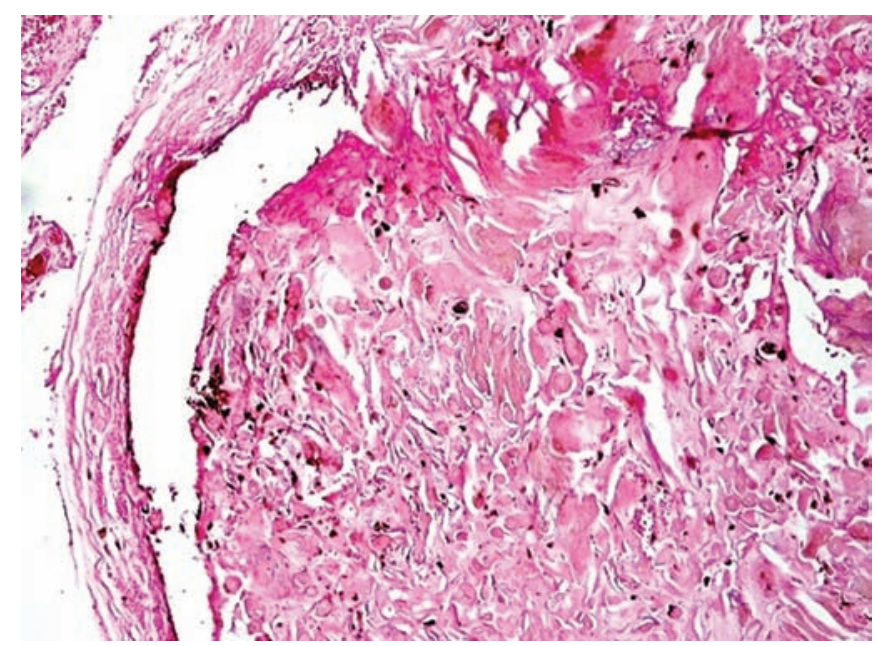

Fig. 3: Lower magnification shows a cystic lesion associated with odontoma. Notice the presence of ghost cells and tooth-like structures 


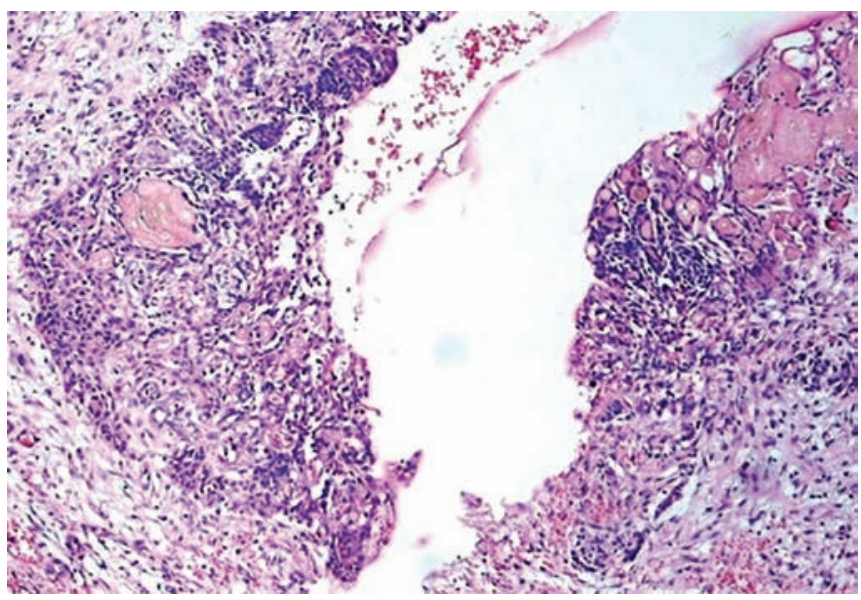

Fig. 4: Medium magnification indicates ameloblastomatous type characterized by a unicystic structure lined by multifocal intraluminal epithelial proliferations along with clusters of ghost cells

ameloblastomatous portion did not contain any ghost cells or calcification, and juxtaepithelial dentinoid was not present. These latter features differentiated the lesion from ameloblastomatous COC. However, several clusters of ghost cells surrounded by foreign body-type giant cell along with calcified materials and dentinoid formation could be seen in the fibrous connective tissue. (2) The COC associated with other odontogenic tumors in two cases [one case of ameloblastic fibroma (Fig. 6) and one case of ameloblastic fibro-odontoma (Fig. 7)]. (3) Central epithelial odontogenic ghost cell tumor (2 cases; $3.8 \%)$ which showed cystic epithelium with nests and clusters of transformed ameloblastomatous portions in cyst wall containing ghost cells, calcifications, and dentinoid formation (Fig. 8). (4) Peripheral epithelial odontogenic ghost cell tumor (2 cases; $3.8 \%$ ), which occurred on the gingiva and resembled peripheral ameloblastoma except for clustered ghost cells in the central portion of follicular islands and the presence of juxtaepithelial dentinoid (Fig. 9). In our series, there was no lesion with malignant changes. ${ }^{8-10}$ Table 2 shows the 52 cases of COC.

\section{DISCUSSION}

In this study, 52 cases of COC were studied. Among them, 31 cases occurred in males, and 21 cases occurred in females. These findings are in agreement with those of
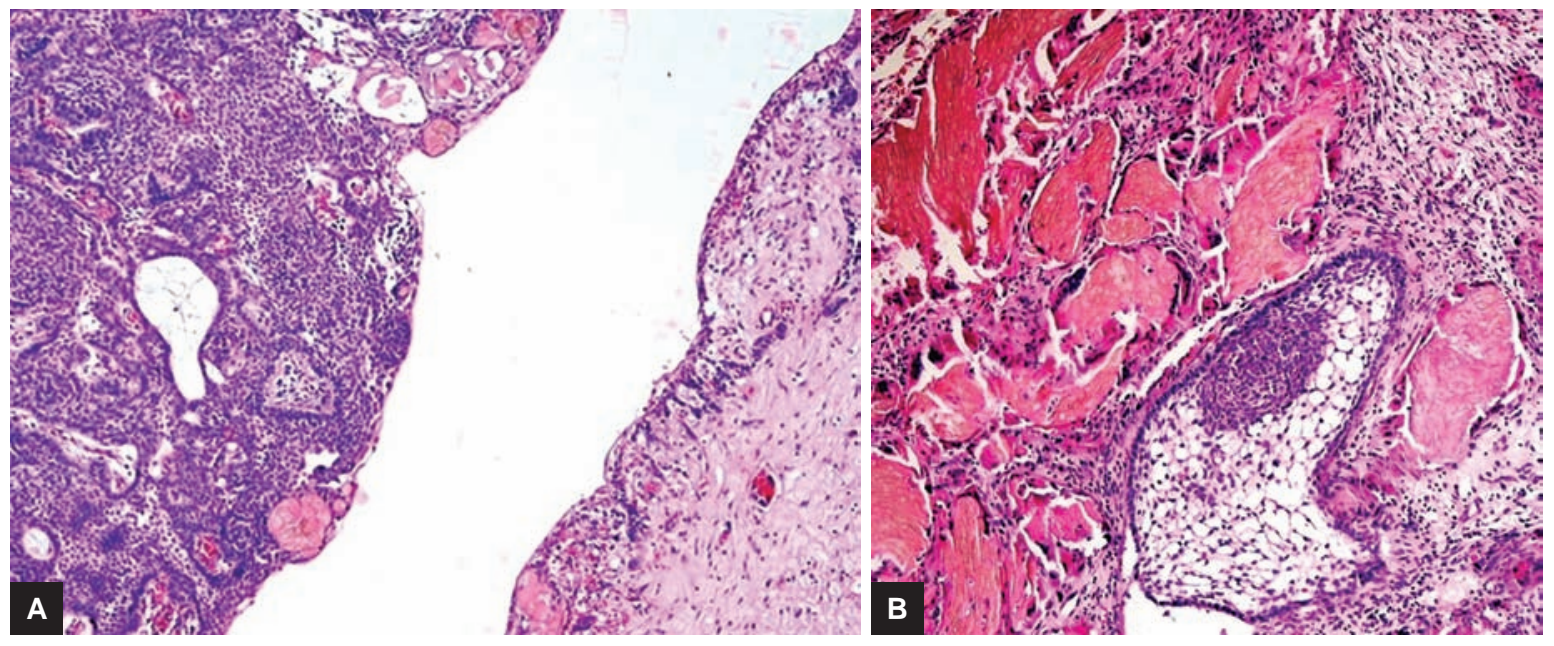

Figs 5A and B: (A) Lower magnification shows ameloblastoma ex-COC with a cystic structure lined by odontogenic epithelium. Notice the ameloblastomatous changes with plexiform pattern and ghost cells; and (B) Higher magnification shows ameloblastoma ex-COC with a huge amount of ghost cells and ameloblastomatous proliferation in the follicular pattern

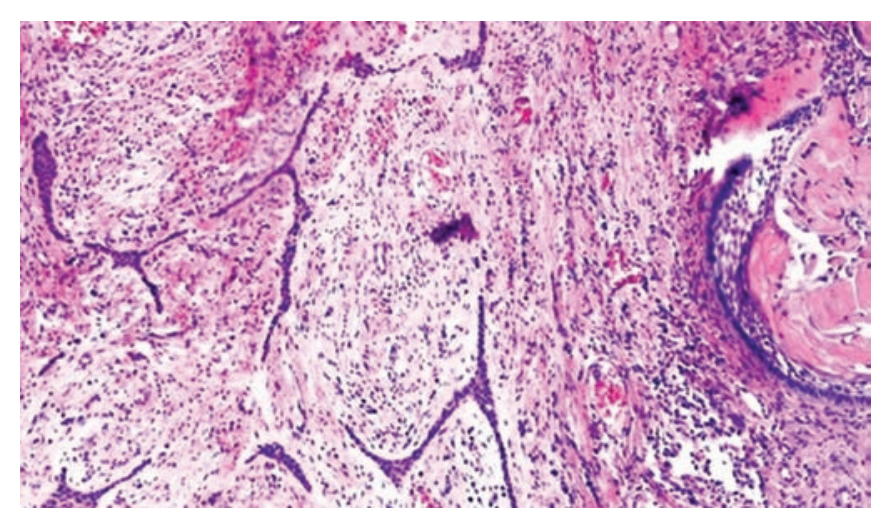

Fig. 6: Lower magnification shows COC associated with ameloblastic fibroma

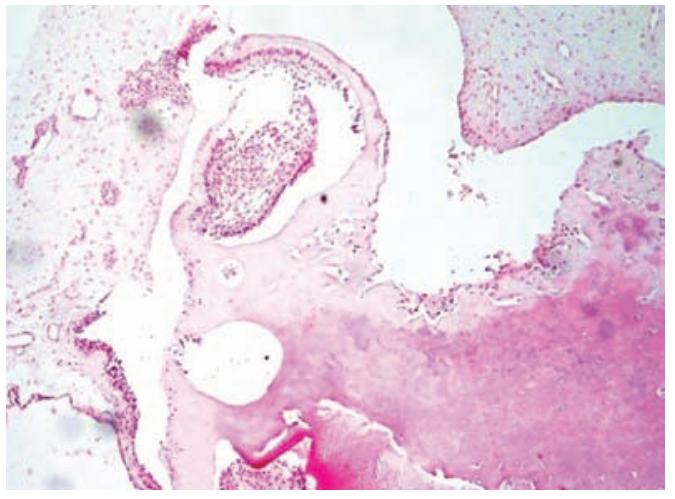

Fig. 7: Lower magnification view of COC with ameloblastic fibro-odontoma 


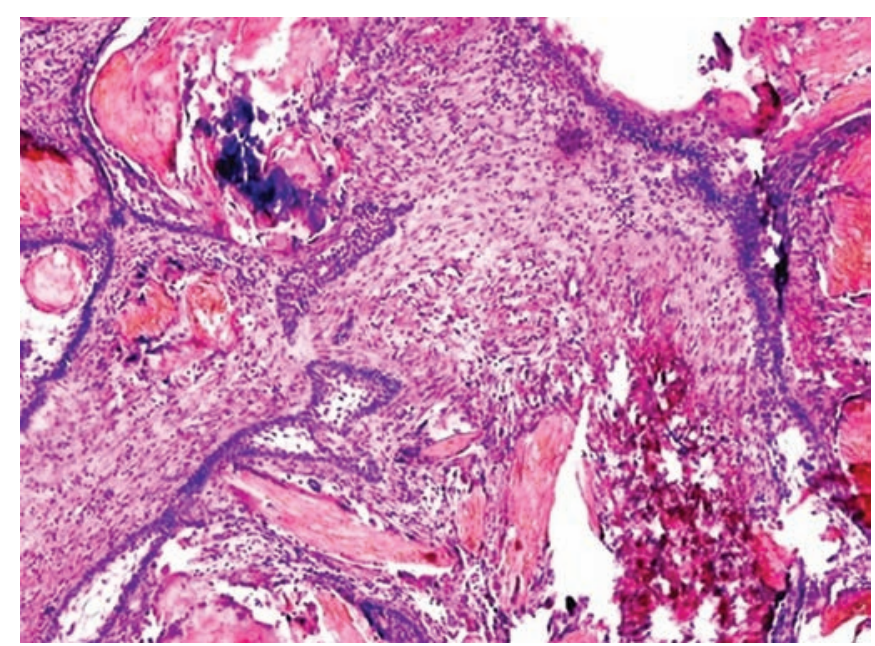

Fig. 8: Lower magnification of central epithelial odontogenic ghost cell tumor which shows a cystic epithelium with nests of transformed ameloblastomatous portions containing ghost cells, calcifications, and dentinoid formation

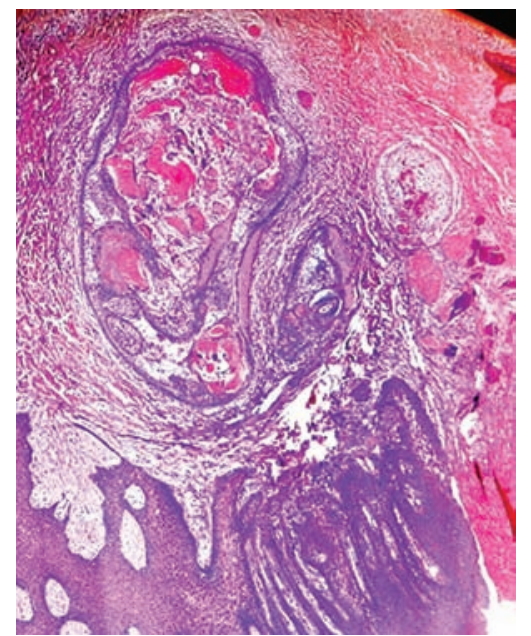

Fig. 9: Lower magnification view shows peripheral epithelial odontogenic ghost cell tumor, with clustered ghost cells and dentinoid materials in the follicular island

Table 2: A demographic profile of 52 patients with COC

\begin{tabular}{|c|c|c|c|c|c|}
\hline $\begin{array}{l}\text { Case } \\
\text { number }\end{array}$ & Gender & Age & Anatomical site & Radiographic findings & Histopathologic variant \\
\hline 1 & $\mathrm{~F}$ & 19 & Maxillary left canine & Unilocular radiolucent area & Simple cyst \\
\hline 2 & $\mathrm{~F}$ & 25 & Maxillary right premolars & Unilocular radiolucent area & Simple cyst \\
\hline 3 & M & 15 & Mandibular right premolars & Unilocular radiolucent area & Simple cyst \\
\hline 4 & M & 29 & Mandibular right molars & Unilocular radiolucent area & Simple cyst \\
\hline 5 & M & 32 & Mandibular right molars & Unilocular radiolucent area & Simple cyst \\
\hline 6 & $\mathrm{~F}$ & 27 & Mandibular right premolars & Unilocular radiolucent area & Simple cyst \\
\hline 7 & $\mathrm{~F}$ & 25 & Mandibular right molars & Unilocular radiolucent area & Simple cyst \\
\hline 8 & M & 34 & Mandibular right premolars & Unilocular radiolucent area & Simple cyst \\
\hline 9 & M & 17 & Mandibular left premolars & Unilocular radiolucent area & Simple cyst \\
\hline 10 & M & 26 & Maxillary right premolars & Unilocular radiolucent area & Simple cyst \\
\hline 11 & M & 53 & Mandibular right molars & Unilocular radiolucent area & Simple cyst \\
\hline 12 & $\mathrm{~F}$ & 22 & Mandibular right molars & Unilocular radiolucent area & Simple cyst \\
\hline 13 & $\mathrm{~F}$ & 18 & Maxillary midline & Unilocular radiolucent area & Simple cyst \\
\hline 14 & $\mathrm{~F}$ & 15 & Mandibular left premolars & Unilocular radiolucent area & Simple cyst \\
\hline 15 & $\mathrm{~F}$ & 19 & Mandibular left molars & Unilocular radiolucent area & Simple cyst \\
\hline 16 & $\mathrm{~F}$ & 22 & Maxillary left incisors & Unilocular radiolucent area & Simple cyst \\
\hline 17 & $\mathrm{~F}$ & 45 & Mandibular right premolars & Unilocular radiolucent area & Proliferative cyst \\
\hline 18 & $\mathrm{~F}$ & 48 & Mandibular midline & Unilocular radiolucent area & Proliferative cyst \\
\hline 19 & $\mathrm{~F}$ & 28 & Maxillary left premolars & Unilocular radiolucent area & Proliferative cyst \\
\hline 20 & $\mathrm{~F}$ & 34 & Maxillary left premolars & Unilocular radiolucent area & Proliferative cyst \\
\hline 21 & M & 33 & Maxillary right premolars & Unilocular radiolucent area & Proliferative cyst \\
\hline 22 & M & 20 & Maxillary right incisors & Unilocular radiolucent area & Proliferative cyst \\
\hline 23 & M & 33 & Maxillary midline & Unilocular radiolucent area & Proliferative cyst \\
\hline 24 & M & 25 & Mandibular right molars & Unilocular radiolucent area & Proliferative cyst \\
\hline 25 & $\mathrm{~F}$ & 19 & Mandibular right molars & Mixed radiolucent-radiopaque & Simple cyst associated with odontoma \\
\hline 26 & $\mathrm{~F}$ & 9 & Maxillary left premolars & Mixed radiolucent-radiopaque & Simple cyst associated with odontoma \\
\hline 27 & $\mathrm{~F}$ & 16 & Maxillary right canine & Mixed radiolucent-radiopaque & Simple cyst associated with odontoma \\
\hline 28 & $\mathrm{~F}$ & 22 & Mandibular left premolars & Mixed radiolucent-radiopaque & Simple cyst associated with odontoma \\
\hline 29 & M & 27 & Mandibular right molars & Mixed radiolucent-radiopaque & Simple cyst associated with odontoma \\
\hline 30 & M & 30 & Mandibular right molars & Mixed radiolucent-radiopaque & Simple cyst associated with odontoma \\
\hline 31 & M & 15 & Mandibular left molars & Mixed radiolucent-radiopaque & Simple cyst associated with odontoma \\
\hline 32 & M & 23 & Mandibular right molars & Mixed radiolucent-radiopaque & Simple cyst associated with odontoma \\
\hline 33 & M & 8 & Maxillary left incisors & Mixed radiolucent-radiopaque & Simple cyst associated with odontoma \\
\hline 34 & M & 27 & Mandibular right molars & Mixed radiolucent-radiopaque & Simple cyst associated with odontoma \\
\hline
\end{tabular}

(Cont'd...) 


\begin{tabular}{|c|c|c|c|c|c|}
\hline $\begin{array}{l}\text { Case } \\
\text { number }\end{array}$ & Gender & Age & Anatomical site & Radiographic findings & Histopathologic variant \\
\hline 35 & $\mathrm{M}$ & 28 & Mandibular right molars & Mixed radiolucent-radiopaque & Simple cyst associated with odontoma \\
\hline 36 & M & 30 & Mandibular right molars & Mixed radiolucent-radiopaque & Simple cyst associated with odontoma \\
\hline 37 & M & 19 & Maxillary midline & Mixed radiolucent-radiopaque & Simple cyst associated with odontoma \\
\hline 38 & M & 8 & Maxillary left incisors & Mixed radiolucent-radiopaque & Simple cyst associated with odontoma \\
\hline 39 & $\mathrm{~F}$ & 22 & $\begin{array}{l}\text { Mandibular right premolars to } \\
\text { molars }\end{array}$ & Mixed radiolucent-radiopaque & Simple cyst associated with odontoma \\
\hline 40 & $\mathrm{~F}$ & 30 & Maxillary left premolars & Mixed radiolucent-radiopaque & Simple cyst associated with odontoma \\
\hline 41 & M & 13 & Mandibular left premolars & Unilocular radiolucent area & Ameloblastomatous COC \\
\hline 42 & M & 61 & Mandibular left molars & Unilocular radiolucent area & Ameloblastomatous COC \\
\hline 43 & M & 35 & Mandibular left molars & Unilocular radiolucent area & Ameloblastomatous COC \\
\hline 44 & $\mathrm{~F}$ & 50 & Mandibular right molars & Mixed radiolucent-radiopaque & Ameloblastoma ex COC \\
\hline 45 & $\mathrm{M}$ & 52 & Maxillary midline & Mixed radiolucent-radiopaque & Ameloblastoma ex COC \\
\hline 46 & $\mathrm{~F}$ & 20 & Maxillary left incisors & Mixed radiolucent-radiopaque & Ameloblastoma ex COC \\
\hline 47 & M & 28 & Mandibular left molars & Unilocular radiolucent area & Associated with ameloblastic fibroma \\
\hline 48 & M & 25 & Mandibular left molars & Mixed radiolucent-radiopaque & $\begin{array}{l}\text { Associated with ameloblastic fibro- } \\
\text { odontoma }\end{array}$ \\
\hline 49 & M & 28 & Maxillary left incisors & Mixed radiolucent-radiopaque & Odontogenic ghost cell tumor \\
\hline 50 & M & 25 & Mandibular left molars & Mixed radiolucent-radiopaque & Odontogenic ghost cell tumor \\
\hline 51 & M & 61 & Mandibular left premolars & - & Peripheral COC \\
\hline 52 & $\mathrm{M}$ & 59 & Mandibular right premolars & - & Peripheral COC \\
\hline
\end{tabular}

Hong et $\mathrm{al}^{8}$ study. The cyst can occur at any age; however, most of the cases have been found before age $40 .{ }^{11} \mathrm{In}$ this study, of the 44 cases, $84.6 \%$ of cases occurred before age 40 . In this study, only $36.5 \%$ of cases were found in the maxilla. However, previous studies had indicated the maxilla and mandible being affected equally. ${ }^{10,12}$

There are two concepts for COC classification. The first concept "the monistic" one classifies all COCs as neoplastic lesions even when they appear as cystic lesions. The second concept "dualistic" classifies all COCs as two entities: cyst and neoplasm. ${ }^{13}$ Fejerskov and $\mathrm{Krogh}^{14}$ supported the dualistic concept. Abrams and Howell believed that due to multipotentiality of odontogenic epithelium, it is expected to see the collision lesions. ${ }^{13}$ However, the WHO classified COC as the monistic concept. ${ }^{15}$ Calcifying cystic odontogenic tumors can be found centrally (intraosseous) or peripherally (extraosseous); therefore, they are believed to arise from odontogenic epithelial remnants trapped within the jaw bones or gingival tissues. ${ }^{16}$ Freedman et $\mathrm{al}^{12}$ suggested that the tumor cells originate from well-differentiated ameloblasts which have neural crest origin with pluripotential capacity. Praetorius et $\mathrm{al}^{17}$ and Buchner ${ }^{10}$ believed that the reduced enamel organ, or islands of odontogenic epithelium within the tooth follicle, or the remnants of the odontogenic epithelium in the bone or gingival tissue can be the source of the neoplastic cells of CCOT. Altini and Farman ${ }^{6}$ suggested the dental lamina rests (rests of Serres) as the origin of COC. The remnants of the dental lamina and surface epithelium have been considered as two major sources for the origin of extraosseous
CСOT. ${ }^{18}$ The remnants of the dental lamina and surface epithelium have been suggested as the histogenesis of gingival cyst of adults and peripheral ameloblastoma. ${ }^{19}$ Ameloblastoma can also be found as both intraosseous lesion (solid or multicystic, and unicystic) and extraosseous (peripheral) lesion. Multicystic/solid type is more aggressive than unicystic and peripheral types. ${ }^{20}$ These finding may indicate some similarities between odontogenic lesions, especially ameloblastoma, and some variants of $\mathrm{COC}$ which show ameloblastomatous transformation. Ghost cells and calcification, dentinoid formation are other features in COC. Gorlin et $\mathrm{al}^{1}$ considered them as an inflammatory response. However, Abrams and Howell proposed them as induction of ghost cells in granulation tissue. $\mathrm{Ng}$ et $\mathrm{al}^{21}$ proposed ghost cell as a metaplastic change in the connective tissue without the participation of granulation tissue. Barnes et $\mathrm{al}^{4}$ explained CCOT as an extremely rare benign cystic neoplasm characterized by an ameloblastoma-like epithelium and ghost cells that have the potential to undergo calcification. The presence of cholesterol clefts in the connective tissue may be a proof for foreign body reaction in the cyst wall. Epithelial budding and migration of ghost cells from epithelial lining also occur in COC. . $^{810}$ Coexistence of COCs with other odontogenic lesions has been reported, which raises the question whether these features are secondary phenomena in preexisting COCs or the COCs develop secondarily in preexisting other odontogenic lesions; ${ }^{22}$ however, several investigations believed that proliferating epithelial odontogenic islands may induce the mesenchymal tissue to develop 
other odontogenic tumors. ${ }^{23-25}$ Ameloblastomatous $\mathrm{COC}$ is different from true ameloblastoma arising in COC as despite ameloblastoma ex-COC, the ghost cells and dystrophic calcification can be observed within the proliferative epithelium. The coexistence of COC with odontoma is controversial. While some studies suggest that COC develops secondarily from odontogenic epithelium which forms the odontoma, others believe that as odontogenic epithelium has the potential for mesenchymal induction, the odontoma develops secondarily from the lining epithelium of the COC. The latter concept can explain the coexistence of some other odontogenic tumors, such as ameloblastic fibro-odontoma and ameloblastic fibroma with COCs, even though this concept can explain the dentin formation in COCs. ${ }^{8,17,22,26}$ Another lesion is DGCT. ${ }^{27}$ Some odontogenic lesions include calcifying epithelial odontogenic tumor, ameloblastic fibroodontoma, and adenomatoid odontogenic tumor. For the lesions with little or no mineralization, dentigerous cyst can be considered in differential diagnosis of CCOT. ${ }^{10,28}$ Surgical enucleation, curettage, and marsupialization are the selected treatment approaches, but the ameloblastomatous CCOT should be treated like an ameloblastoma. ${ }^{29}$

\section{CONCLUSION}

There are two different histopathological entities. One is defined by the presence of a cystic lesion, and the other is an infiltrative lesion with some degree of odontogenic epithelium islands and varying masses of ghost cells and dentinoid materials in the stroma. In view of these findings, it is very difficult to determine every lesion that has a cystic architecture is truly cystic or is a neoplastic one in nature. It is believed that the solid variants may be neoplastic.

\section{REFERENCES}

1. Gorlin RJ, Pindborg JJ, Odont, Clausen FP, Vickers RA. The calcifying odontogenic cyst - a possible analogue of the cutaneous calcifying epithelioma of Malherbe. An analysis of fifteen cases. Oral Surg Oral Med Oral Pathol 1962 Oct;15:1235-1243.

2. deLimaAP,KitakawaD,AlmeidaJD, BrandãoAA,AnbinderAL. Peripheral calcifying cystic odontogenic tumour of the maxillary gingiva. BMC Res Notes 2012 Aug;5:455.

3. Bafna SS, Joy T, Tupkari JV, Landge JS. Dentinogenic ghost cell tumor. J Oral Maxillofac Pathol 2016 Jan-Apr;20(1):163.

4. Barnes, LE.; Reichart, P.; Sidransky, D. WHO classification of tumors: pathology and genetics of tumors of the head and neck. Lyon: IARC; 2005.

5. Ledesma-Montes C, Gorlin RJ, Shear M, Torius FP, MosquedaTaylor A, Altini M, Unni K, Paes de Almeida O, Carlos-Bregni R, Romero de León E, et al. International collaborative study on ghost cell odontogenic tumours: calcifying cystic odontogenic tumour, dentinogenic ghost cell tumour and ghost cell odontogenic carcinoma. J Oral Pathol Med 2008 May;37(5): 302-308.
6. Altini M, Farman AG. The calcifying odontogenic cyst. Eight new cases and a review of the literature. Oral Surg Oral Med Oral Pathol 1975 Dec;40(6):751-759.

7. Scott J, Wood GD. Aggressive calcifying odontogenic cyst-a possible variant of ameloblastoma. Br J Oral Maxillofac Surg 1989 Feb;27(1):53-59.

8. Hong SP, Ellis GL, Hartman KS. Calcifying odontogenic cyst. A review of ninety-two cases with reevaluation of their nature as cysts or neoplasms, the nature of ghost cells, and subclassification. Oral Surg Oral Med Oral Pathol 1991 Jul;72(1):56-64.

9. Neville, BD.; Allen, C.; Chi, A. Oral and maxillofacial pathology. 4th ed. China: Elsevier; 2016.

10. Buchner A. The central (intraosseous) calcifying odontogenic cyst: an analysis of 215 cases. J Oral Maxillofac Surg 1991 Apr;49(4):330-339.

11. Desai RS, Sabnis R, Bhuta BA, Yadav A. Calcifying cystic odontogenic tumor in a 5-year-old boy: a case report. J Maxillofac Oral Surg 2015 Mar;14 Suppl 1:348-351.

12. Freedman PD, Lumerman H, Gee JK. Calcifying odontogenic cyst. A review and analysis of seventy cases. Oral Surg Oral Med Oral Pathol 1975 Jul;40(1):93-106.

13. Manchanda AS, Narang RS. Calcifying odontogenic cyst: dilemma in classification. NY State Dent J 2014 Apr;80(3):27-29.

14. Fejerskov $\mathrm{O}, \mathrm{Krogh}$ J. The calcifying ghost cell odontogenic tumor - or the calcifying odontogenic cyst. J Oral Pathol 1972 Nov;1(6):273-287.

15. Menat S, Md S, Attur K, Goyal K. Ameloblastomatous CCOT: a case report of a rare variant of CCOT with a review of the literature on its diverse histopathologic presentation. Case Rep Dent 2013 Aug;2013:407656.

16. Kler S, Palaskar S, Shetty VP, Bhushan A. Intraosseous calcifying cystic odontogenic tumor. J Oral Maxillofac Pathol 2009 Jan-Jun;13(1):27-29.

17. Praetorius F, Hjørting-Hansen E, Gorlin RJ, Vickers RA. Calcifying odontogenic cyst. Range, variations and neoplastic potential. Acta Odontol Scand 1981 Feb;39(4):227-240.

18. Manor Y, Mardinger O, Katz J, Taicher S, Hirshberg A. Peripheral odontogenic tumours - differential diagnosis in gingival lesions. Int J Oral Maxillofac Surg 2004 Apr;33(3):268-273.

19. Mittal N, Sah K, Chandra S, Gupta S, Mittal S, Agarwal M. Extraosseous calcifying cystic odontogenic tumor: an uncommon variant. Natl J Maxillofac Surg 2013 Jul;4(2):245-248.

20. Carlson ER, Marx RE. The ameloblastoma: primary, curative surgical management. J Oral Maxillofac Surg 2006 Mar;64(3):484-494.

21. $\mathrm{Ng} \mathrm{KH}$, Siar $\mathrm{CH}$. Odontogenic keratocyst with dentinoid formation. Oral Surg Oral Med Oral Pathol Oral Radiol Endod 2003 May;95(5):601-606.

22. Yoon JH, Kim HJ, Yook JI, Cha IH, Ellis GL, Kim J. Hybrid odontogenic tumor of calcifying odontogenic cyst and ameloblastic fibroma. Oral Surg Oral Med Oral Pathol Oral Radiol Endod 2004 Jul;98(1):80-84.

23. Takeda Y, Suzuki A, Yamamoto H. Histopathologic study of epithelial components in the connective tissue wall of unilocular type of calcifying odontogenic cyst. J Oral Pathol Med 1990 Mar;19(3):108-113.

24. Premalatha BR, Patil S, Rao RS, Reddy NP, Indu M. Odontogenic tumor markers - an overview. J Int Oral Health 2013 Apr;5(2):59-69.

25. Lee SK, Kim YS. Current concepts and occurrence of epithelial odontogenic tumors: II. Calcifying epithelial 
odontogenic tumor versus ghost cell odontogenic tumors derived from calcifying odontogenic cyst. Korean J Pathol 2014 Jun;48(3):175-187.

26. Hirshberg A, Kaplan I, Buchner A. Calcifying odontogenic cyst associated with odontoma: a possible separate entity (odontocalcifying odontogenic cyst). J Oral Maxillofac Surg 1994 Jun;52(6):555-558.

27. Rai S, Prabhat M, Goel S, Bhalla K, Panjwani S, Misra D, Agarwal A, Bhatnagar G. Dentinogenic ghost cell tumor - a neoplastic variety of calcifying odontogenic cyst: case presentation and review. N Am J Med Sci 2015 Jan;7(1):19-23.

28. Utumi ER, Pedron IG, da Silva LP, Machado GG, Rocha AC. Different manifestations of calcifying cystic odontogenic tumor. Einstein (Sao Paulo) 2012 Jul/Sep;10(3):366-370.

29. Rawson KK, Patel N, Sandesara Y. Proliferative ameloblastomatous calcifying cystic odontogenic tumor of the mandible: a rare histological variant. J Indian Acad Oral Med Radiol 2015 Nov;27(2):278-281. 